\title{
Revisão textual pelo viés dialógico na formação docente inicial
}

\section{Text revision by the dialogical bias in teachers' initial formation}

\section{Revisión textual por la perspectiva dialógico en la formación docente inicial}

\author{
iD (9) Paulo Cezar Czerevaty \\ Programa de Pós-Graduação em Letras - Universidade Estadual do Centro-Oeste \\ (UNICENTRO), Irati, Paraná, Brasil, \\ E-mail: pauloivai@hotmail.com
}

(iD) Cristiane Malinoski Pianaro Angelo Universidade Estadual do Centro-Oeste (UNICENTRO), Irati, Paraná, Brasil. E-mail: cristiane.mpa@gmail.com

iD Renilson José Menegassi Universidade Estadual de Maringá (UEM), Maringá, Paraná, Brasil. E-mail: renilson@wnet.com.br

Resumo: Sustentados pelos pressupostos do dialogismo do Círculo de Bakhtin e pelas suas (re)enunciações na Linguística Aplicada, objetiva-se discutir aspectos do processo de revisão textual pela perspectiva dialógica, na formação docente inicial. Para tanto, são analisados três registros de um estudo de caso realizado na graduação em Letras, em que se problematiza a confluência entre teoria dialógica, metodologias e práticas para execução do processo. Os resultados demonstram que: a) a escolha metodológica não define o processo como dialógico ou não-dialógico; b) os conceitos embasadores da concepção dialógica orientam produtivamente a intervenção no texto e a seleção metodológica.

Palavras-chave: Revisão textual. Dialogismo. Formação docente. 
Abstract: Supported by the assumptions of the dialogism of the Bakhtin Circle and its (re)enunciations in Applied Linguistics, the objective is to discuss aspects of the textual review process from the dialogical perspective in the teachers' initial formation. For this, three records of a case study conducted at the graduation in Language and Literature Course are analyzed, in which is problematized the confluence between dialogical theory, methodologies and practices for the execution of the process. The results demonstrate that: a) the methodological choice does not define the process as dialogical or non-dialogical; b) the concepts that support the dialogical conception productively guide the intervention in the text and the methodological selection.

Keywords: Textual review. Dialogism. Teacher education.

Resumen: Apoyados en los postulados del dialogismo del Círculo de Bakhtin y por sus (re) enunciaciones en la Lingüística Aplicada, buscamos discutir los aspectos del proceso de revisión textual por la perspectiva dialógica, en la formación docente inicial. Para ello, son analizados tres registros de un estudio de caso realizado en la licenciatura en Letras, en el que se problematiza la confluencia entre teoría dialógica, metodologías y prácticas para ejecución del proceso. Los resultados demuestran que: a) la elección no define el proceso como dialógico o nodialógico; b) los conceptos fundantes de la concepción dialógica orientan productivamente la intervención en el texto y la selección metodológica.

Palabras-clave: Revisión textual. Dialogismo. Formación docente.

Submetido em 21 de setembro de 2020.

Aceito em 05 de novembro de 2020.

Publicado em 03 de setembro de 2021. 


\section{Considerações iniciais}

Este artigo, sustentado pelo viés do dialogismo do Círculo de Bakhtin (BAKHTIN, 2016a [1976]; BAKHTIN, 2016b [1978]; BAKHTIN, 2017 [1975]; VOLOCHINOV, 2013a [1930]; VOLOCHINOV, 2013b [1926]; VOLÓCHINOV, 2017 [1929]) e em suas (re)enunciações na Linguística Aplicada do Brasil, no que se refere à produção textual escrita (GERALDI, 2016; MENEGASSI; GASPAROTTO, 2019; 2020; MENEGASSI, 2016; SOBRAL; GIACOMELLI, 2016), caracteriza o trabalho como revisão textual pela perspectiva dialógica, na formação docente inicial, em nível superior de ensino. O objetivo é discutir como a orientação teórica norteada pelo dialogismo, nesse contexto específico, orienta a leitura do texto a ser revisado pelo docente em formação e suas correspondentes abordagens metodológicas e práticas de trabalho com a revisão.

Parte-se da compreensão de que o processo de revisão textual, conforme discutido em trabalhos da área (MENEGASSI; GASPAROTTO, 2019, 2020), pode ser equivocadamente interpretado pelo docente como uma etapa apenas de aplicação de algumas metodologias de revisão mais ou menos adequadas à concepção dialógica de ensino com a linguagem e não como um exercício de análise dos elementos que definem o texto de um gênero discursivo em específico, a fim de eleger as maneiras mais adequadas de intervenção. Essa análise, de acordo com a perspectiva adotada neste artigo, depende da compreensão e emprego de alguns conceitos do dialogismo como aspectos inerentes ao processo docente de revisão textual.

Para a compreensão prática desses conceitos, são analisados três registros de um estudo de caso realizado no contexto de formação na graduação em Letras, de uma universidade pública da região Sudeste do Paraná, num total de seis sujeitos participantes. Esses registros são revisões efetuadas por um dos docentes em três textos: 1) gênero fábula, disponibilizado pelos pesquisadores, considerado etapa inicial da pesquisa; 2) gênero conto de terror, 
retirado de um trabalho relatado por Menegassi e Gasparotto (2020), etapa intermediária de intervenção da pesquisa; c) gênero crônica, advindo do estágio obrigatório realizado pelo acadêmico participante, etapa final de intervenção da pesquisa. A partir desses exemplos, discute-se como são estabelecidas as relações entre os conceitos teóricos que embasam a revisão pela perspectiva dialógica, a intervenção do professor no texto oferecido e, com isso, a escolha metodológica de abordagem definida por esse sujeito de pesquisa.

Ressalte-se que a pesquisa relatada foi aprovada pelo COMEP - Comitê de Ética em Pesquisa, sob o parecer nº 2.850.150 (UNICENTRO), de 28 de agosto de 2018.

\section{Aspectos do dialogismo na revisão textual}

De acordo com Fuza, Ohushi e Menegassi (2011), o processo de ensino e aprendizagem fundamentado em conceitos dialógicos atribui centralidade ao texto enquanto manifestação de materialidade linguística do discurso e, por consequência, a possibilidade de interação entre professor e aluno. Pela perspectiva de Bakhtin (2016a [1976]), compreende-se o texto como a união de dois aspectos: a) a materialidade em que é produzido, apresentado, recebido; b) a cadeia infinita, ininterrupta e irreproduzível que está presente em todo texto e que é formada, também, pela sua vinculação e perpetuação social. Dessa forma, o texto é o registro dialógico de marcas linguísticas e de marcas enunciativas (SOBRAL; GIACOMELLI, 2016), sobre o qual se evidencia o trabalho de revisão textual.

A filosofia dialógica do Círculo de Bakhtin se desdobra, nos estudos brasileiros, em seus primórdios iniciais, em concepção de linguagem como forma de interação e, no que diz respeito à produção escrita, em concepção de escrita como trabalho (GERALDI, 1984; GERALDI, 1997 [1991], FIAD; MAYRINK-SABINSON, 1991; MENEGASSI, 2016). Nessa concepção, são considerados os instru- 
mentos - neste caso, linguísticos, textuais e discursivos - e seu manejo mediante as condições de produção, portanto, a efetiva constituição de uma ação, um trabalho com e sobre a língua escrita. Isso se realiza, sobretudo, pela efetivação de algumas etapas que exigem o esforço e o domínio dos sujeitos envolvidos: 1) planejamento; 2) execução; 3) revisão; 4) reescrita (MENEGASSI, 2013). Este artigo foca na etapa de revisão de textos e, por consequência, na sua reescrita.

Menegassi (2013), ao retomar e discutir os estudos cognitivos sobre a produção de textos (HAYES; FLOWER, 1980), argumenta que revisão e reescrita são processos complementares, pois existem pela reciprocidade e têm por objetivo propiciar qualidade ao texto produzido. Compreende-se que, nessas etapas, a ênfase não é dada em um produto passível apenas de correções pontuais para sua finalização; pelo contrário, foca-se no processo de construção do texto enquanto uma unidade do discurso (BAKHTIN, 2016b [1978]). Assim, revisar consiste em avançar uma etapa processual da produção escrita, que faz sentido apenas pela concretização da reescrita, com seus acréscimos em relação à produção inicial.

A revisão é efetuada por três maneiras: a) pelo professor - tipo de revisão abordado neste trabalho; b) pelo próprio aluno; c) pelos pares, colegas. As abordagens b) e c) são mais complexas, devido ao fato de se realizarem em turmas de alunos já habituados com as revisões efetivadas pelo docente, o que implica constância e práticas adequadas, em execuções conscientes. Com relação à abordagem de revisão a), de acordo com Geraldi (2016), no momento de sua execução, o professor deixa de ser um mero avaliador e passa a coautor do texto do seu aluno, pois busca dialogar dentro dos limites do texto em que insere seu interesse pela palavra do indivíduo autor.

A revisão realizada pelo professor pode ser efetuada por abordagens variadas, a depender de quais são os objetivos previamente construídos. Serafini (1995) aponta algumas metodologias de correção envolvidas no processo de revisão: correção indicativa, correção resolutiva e correção classificatória. Na correção indica- 
tiva, são marcados os erros ou os pontos que não estão claros no corpo do texto. Na correção resolutiva, o professor, além de sinalizar, resolve o problema para o produtor do texto. Esses dois primeiros tipos são habitualmente mais ligados às correções tradicionais, de cunho puramente formal, a alterar apenas a superfície textual. Já a correção classificatória consiste em catalogar os desvios, a criar sinalizações reconhecíveis pelos alunos, de maneira com que ele mesmo possa solucioná-los.

Ruiz (1998) acrescenta a essas metodologias a correção textual-interativa, por vezes, considerada, de certa maneira, uma parte da metodologia com viés interativo e, até mesmo, dialógico. Essa abordagem de revisão é efetivada por bilhetes orientadores que têm por objetivo interagir com o aluno a respeito da construção do texto. Menegassi e Gasparotto (2020) ampliaram as discussões dessa perspectiva e apontam três formas possíveis de realização da revisão textual-interativa: 1) questionamento - chama-se a atenção do aluno ao problema por meio de perguntas; 2 ) apontamento - recurso objetivo que evidencia a existência de um problema; 3) comentário - forma mais completa, a congregar os itens anteriores e buscar maior elucidação devido à sua natureza e extensão.

Neste artigo, compreende-se que a revisão textual, além da aplicação de alguma das abordagens citadas, apresenta a possibilidade de mobilização de conceitos dialógicos que orientam o professor, de acordo com as marcas linguísticas e as enunciativas do texto (BAKHTIN, 2016a [1976]; SOBRAL; GIACOMELLI, 2016), de forma a evitar a ambiguidade em diferenciar uma revisão de cunho dialógico de uma revisão tradicional, de caráter meramente linguístico-textual, apenas pelo formato metodológico adotado pelo professor.

Os conceitos mobilizados para a revisão de textos são apresentados no Quadro 1 e discutidos na sequência, a partir dos pressupostos do dialogismo (BAKHTIN, 2016a [1976]; BAKHTIN, 2016b [1978]; BAKHTIN, 2017 [1975]; VOLOCHINOV, 2013a [1930]; VOLOCHINOV, 2013b [1926]; VOLÓCHINOV, 2017 [1929]) e de con- 
siderações de autores da Linguística Aplicada do Brasil a respeito do processo de revisão (BELOTI, 2016; GERALDI, 2016; MENEGASSI; GASPAROTTO, 2019; 2020; MENEGASSI, 2013; SOBRAL; GIACOMELLI, 2016). Dividem-se em duas colunas: “Na leitura do texto do aluno" consiste na observação inicial e no estabelecimento de parâmetros para a "Na construção da revisão após a leitura do texto", em que são adequadas as abordagens metodológicas.

Nessa perspectiva, a leitura do texto do aluno é um momento que precede a intervenção na produção, além de contemplar: a) a identificação dos pontos fortes e dos pontos fracos do texto, com base em pressupostos do dialogismo; b) a análise da relevância dos problemas encontrados mediante os aspectos que definem o texto em uma perspectiva dialógica e a etapa do processo pedagógico; e c) a definição dos elementos textuais que necessitam de alteração. A construção da revisão é um momento posterior à leitura, mas dependente dela. Trata-se do desenvolvimento de uma ação sobre os problemas constatados, mediante mobilização e adequação das formas mais pertinentes de revisão para a especificidade da produção textual em questão e do indivíduo que realizou a escrita. 


\section{Quadro 1: Aspectos da revisão de textos pela perspectiva dialógica}

\begin{tabular}{|c|c|c|}
\hline Conceitos do dialogismo & $\begin{array}{c}\text { Na leitura do texto do } \\
\text { aluno }\end{array}$ & $\begin{array}{c}\text { Na construção da revisão após } \\
\text { a leitura do texto }\end{array}$ \\
\hline $\begin{array}{l}\text { - Palavra; } \\
\text { - Gêneros do discurso; } \\
\text { - Finalidade do texto; } \\
\text { - Responsividade; } \\
\text { - Auditório social; } \\
\text { - Tema; } \\
\text { - Estilo; } \\
\text { - Construção composicional; } \\
\text { - Entonação; } \\
\text { - Valoração; } \\
\text { - Contexto extraverbal. }\end{array}$ & $\begin{array}{l}\text { - A revisão textual leva em } \\
\text { conta, como fator de primeira } \\
\text { ordem, a palavra do aluno, } \\
\text { isto é, o que tem de si no } \\
\text { texto, a palavra própria; } \\
\text { - Percebe, de acordo com } \\
\text { a palavra/discurso, se } \\
\text { há aproximação com a } \\
\text { finalidade do texto, caso } \\
\text { contrário, reflete acerca de } \\
\text { intervenções que aproveitam } \\
\text { a palavra/discurso, mas que } \\
\text { a direcionam melhor aos } \\
\text { objetivos; } \\
\text { - Analisa se a palavra e o texto } \\
\text { estão adequados ao gênero } \\
\text { proposto na atividade; } \\
\text { - Verifica a quem o aluno } \\
\text { é responsivo - quais são } \\
\text { os interlocutores que } \\
\text { vislumbrou para a escrita, } \\
\text { de modo a ampliar, caso } \\
\text { necessário, seu auditório } \\
\text { social; } \\
\text { - Reflete, com base na palavra, } \\
\text { na finalidade, no tema, no } \\
\text { interlocutor e no estilo que } \\
\text { sustentam o texto do aluno, } \\
\text { se a estrutura da composição } \\
\text { está adequada; } \\
\text { - Atenta, de acordo com os } \\
\text { aspectos anteriores, aos } \\
\text { elementos gramaticais. }\end{array}$ & $\begin{array}{l}\text { - Arevisão adequa-se à entonação } \\
\text { que valoriza a palavra/discurso } \\
\text { do aluno, além de ser construída } \\
\text { pela atenção ao contexto } \\
\text { extraverbal das relações com } \\
\text { a atividade, a classe, a escola, a } \\
\text { sociedade e a cultura; } \\
\text { - Evita entonações que intimidam } \\
\text { o aluno, reforçam a doutrina do } \\
\text { certo e do errado ou fornecem } \\
\text { uma compreensão de escrita } \\
\text { como apenas domínio de regras } \\
\text { formais; } \\
\text { - Evita apontar muitas } \\
\text { inadequações de uma só vez, a } \\
\text { estender o processo de revisão; } \\
\text { - Adequa-se ao interlocutor, ao } \\
\text { estágio atual de sua formação, } \\
\text { aos seus conhecimentos prévios, } \\
\text { às suas facilidades e dificuldades; } \\
\text { - Demonstra clareza de modo } \\
\text { que o aluno entenda pela revisão } \\
\text { o que se espera dele na reescrita; } \\
\text { - Orienta a reescrita, seja pelas } \\
\text { intervenções no texto do aluno, } \\
\text { seja pelas orientações dadas } \\
\text { em sala de aula, que explicam o } \\
\text { processo. }\end{array}$ \\
\hline
\end{tabular}

Fonte: Elaborado pelos autores (2020).

O primeiro item pontuado em "Na leitura do texto do aluno" é a palavra/discurso (STELLA, 2005; VOLOCHINOV, 2017 [1929]), em que se considera: a) o que há do universo do aluno na escrita; b) porque escolheu compartilhar determinada situação/questão; c) 
quais as relações entre o que foi dito e o extraverbal (VOLOCHINOV, 2013b [1926]) das relações pedagógicas. Trata-se, portanto, do reconhecimento do aluno enquanto autor de discursos (MENEGASSI; GASPAROTTO, 2019). Observar a palavra inclui, assim, uma predisposição em aceitar o texto independente dos problemas encontrados e buscar chaves para que essa palavra seja evidenciada ao mesmo tempo em que se adequa a outros elementos.

Desses elementos, aos quais a palavra precisa se adequar, sem que necessariamente seja alterada, estão a finalidade do texto e o gênero discursivo (BAKHTIN, 2016b [1978]; MENEGASSI, 2013). Há uma indissociabilidade entre o que se busca atingir com a escrita de um texto e o tipo relativamente estável de enunciado que é utilizado para isso. Portanto, é questão fundamental, dentro das propostas de produção de textos, definir com clareza o gênero discursivo trabalhado, seus limites, suas especificidades, além de mobilizar estes parâmetros no momento da observação para uma revisão, com o intuito de preservar a vontade de dizer do locutor ao mesmo tempo em que a adapta às especificidades da interlocução (BAKHTIN, 2016b [1978]).

Assim, junto a todo gênero, há uma vontade discursiva que busca encontrar respostas e que antecipa as possíveis reações compreensivas do seu interlocutor. Trata-se da responsividade (BAKHTIN, 2016b [1978]), outro conceito a ser levado em conta no processo de revisão pelo viés dialógico, devido à possibilidade de potencializar ou de cercear uma produção escrita mediante o tipo de interlocução estabelecida. Ao escrever um texto, o indivíduo antecipa as possíveis respostas que receberá; nesse caso, a produtividade de uma revisão começa pelo fato de o professor decidir ser responsivo à palavra do aluno ou somente aos aspectos superficiais, pois, com o tempo de interação, torna-se já um implícito que define todas as respostas.

Desse modo, a estrutura da composição do gênero discursivo e os elementos superficiais ocupam também espaço dentro de uma revisão pautada em um movimento descendente por conceitos do dialogismo. Defende-se que as marcas linguístico-textuais 
- ortografia, pontuação, paragrafação etc. - podem se fazer presentes nas revisões, mas sem ocupar a centralidade do processo nem ofuscar as marcas enunciativas discutidas anteriormente (SOBRAL; GIACOMELLI, 2016), para evitar a perpetuação de uma doutrina do certo e do errado.

Os pontos de leitura do texto do aluno já destacados possibilitam a base da construção da revisão após a leitura do texto, caracterizada pela mobilização de outros conceitos, como de entonação (VOLOCHINOV, 2013b [1926]), que envolve maneiras de suscitar compreensões para além daquelas expressadas pelo significado verbal escrito, apenas. Assim, o jeito como o texto é revisado, os elementos abordados e a forma de realização dialogam diretamente tanto com a situação imediata de comunicação pedagógica quanto com o contexto extraverbal. Portanto, faz-se necessário pensar nas características do contexto escolar, nos professores, no histórico do aluno, na compreensão que tem do ensino, para trabalhar propositalmente com os subentendidos, ou seja, com aquilo que não está verbalmente expresso, mas compõe a compreensão do texto e do processo, como uma marca valorativa da língua, normalmente expressa em apontamentos, comentários e questionamentos (MENEGASSI; GASPAROTTO, 2020) produzidos pelo docente na revisão textual.

Essa questão é complementada com a atitude responsiva de antecipação e adequação ao interlocutor (VOLOCHINOV, 2017 [1929]) e da poluição visual (MENEGASSI, 2013) que pode ser gerada por uma revisão inadequada, o que impossibilita uma reescrita produtiva, além de, por vezes, gerar uma entonação que resgata do extraverbal apenas a noção de certo e de errado. Tem-se, ainda, a necessidade de clareza e de orientação para a reescrita, o que inclui: a) a objetividade na abordagem das inadequações ou nas sugestões de aprofundamento; b) o cuidado com os excessos; c) a abertura para réplicas discursivas; d) a comunicação discursiva constante; e) o esclarecimento de que um texto reescrito não é apenas um texto readequado aos padrões de escrita escolar. 
A revisão difere, portanto, da avaliação ou correção textual, pois seu objetivo é tomar o texto como provisório, passível de reflexão, de reformulações, para, num trabalho colaborativo, chegar à versão que atenda ao objetivo comunicativo em questão (MENEGASSI; GASPAROTTO, 2019, p. 09).

A revisão, com os acréscimos da perspectiva dialógica de linguagem, possibilita que, na reescrita, o aluno melhore seu texto, assuma a autoria e fortaleça sua palavra nas interações sociais, pontos que se ressaltam em relação às demais perspectivas teóricas. Para isso, o docente, como destacam Menegassi e Gasparotto (2019): a), conhece a concepção dialógica da língua; b) domina e deixa evidente aos alunos os aspectos que envolvem a produção escrita; c) promove, avalia e avança os níveis de interação pedagógica; d) orienta o aluno a se tornar autor de seu próprio discurso; e) utiliza diversas abordagens metodológicas adequadas às especificidades do contexto e da produção.

Com base nesses pressupostos teórico-metodológicos, realizou-se um estudo de caso no contexto da formação docente inicial, a enfocar a revisão textual. A metodologia empregada é apresentada na seção seguinte e esclarece como foram gerados os registros posteriormente analisados, segundo o conceito de revisão na perspectiva dialógica (MENEGASSI; GASPAROTTO, 2019).

\section{Metodologia de pesquisa}

Os registros apresentados neste artigo são oriundos de um estudo de caso, tipo de investigação empírica que aborda, contextualmente, determinado fenômeno contemporâneo (YIN, 2005). A unidade de análise do caso é constituída por professores em formação inicial em Letras, no trabalho teórico, metodológico e prático com os conceitos de revisão e reescrita, em abordagens de práticas constituídas no processo de escrita como trabalho (GERALDI, 1984; GERALDI, 1997 [1991], FIAD; MAYRINK-SABINSON, 1991; MENEGASSI, 2016). 
A pesquisa foi realizada no terceiro ano do curso de Letras, na disciplina de Linguística Aplicada, de uma universidade pública da região Sudeste do Paraná. Dos seis acadêmicos - aqui considerados docentes em formação - que compunham a turma, três foram participantes ativos, pela presença em todas as etapas propostas para a especificidade da investigação. Destaque-se que, conforme Yin (2005), no estudo de caso, não há fórmulas para a rotina investigativa, o que significa que as etapas e os instrumentos dependem da elaboração de um plano de ação específico para a unidade de análise. O Quadro 2 apresenta as etapas e os procedimentos utilizados na pesquisa.

\section{Quadro 2: Etapas da pesquisa}

\begin{tabular}{|c|c|}
\hline Etapa & Procedimento \\
\hline Levantamento inicial & $\begin{array}{l}\text { - Solicitação aos docentes em formação para realizar a revisão em } \\
\text { textos produzidos por alunos de Ensino Fundamental e Médio; } \\
\text { - Aplicação de questionário com abordagem da relação pessoal } \\
\text { dos alunos com as etapas de revisão e reescrita, o conhecimento } \\
\text { acerca desses conceitos e o entendimento a respeito das } \\
\text { concepções de linguagem e de escrita. }\end{array}$ \\
\hline Ações de intervenção & $\begin{array}{l}\text { - Abordagem de textos teórico-metodológicos a respeito da } \\
\text { escrita como trabalho e das etapas de revisão e de reescrita: } \\
1^{\circ} \text { texto - Portos de passagem (GERALDI, } 1997 \text { [1991]); } 2^{\circ} \text { texto } \\
\text { - Revisão textual-interativa: aspectos teórico-metodológicos } \\
\text { (MENEGASSI; GASPAROTTO, 2016); } 3^{\circ} \text { texto - Da revisão à reescrita: } \\
\text { operações linguísticas sugeridas e atendidas na construção do texto } \\
\text { (MENEGASSI, 2001); } 4^{\circ} \text { texto - Base Nacional Comum Curricular } \\
\text { (BRASIL, 2018); } 5^{\circ} \text { texto - Revisão e reescrita nos documentos oficiais: } \\
\text { conceitos e orientações metodológicas (MENEGASSI; GASPAROTTT, } \\
\text { 2014); } 6^{\circ} \text { texto - Como escrever textos (SERAFINI, 1995); } \\
\text { - Realização de atividades de revisão e de reescrita em textos de } \\
\text { alunos do Ensino Básico selecionados pelos pesquisadores; } \\
\text { - Acompanhamento dos pesquisadores nos estágios realizados } \\
\text { pelos docentes em formação; } \\
\text { - Auxílio dos pesquisadores na revisão dos textos produzidos } \\
\text { pelas turmas em que os docentes em formação realizaram seus } \\
\text { estágios. }\end{array}$ \\
\hline
\end{tabular}


Levantamento final

- Aplicação aos docentes em formação de atividades de revisão em textos escritos por alunos de Ensino Fundamental e de Ensino Médio;

- Aplicação de questionário com abordagem da relação pessoal dos alunos com as etapas de revisão e reescrita, o conhecimento acerca desses conceitos e o entendimento a respeito das concepções de linguagem e de escrita.

Fonte: Elaborado pelos autores (2020).

Os registros analisados são três e advêm: a) do levantamento inicial - realização de revisão em textos escritos por alunos de Ensino Fundamental e Ensino Médio; b) das ações de intervenção - acompanhamento dos pesquisadores nos estágios realizados pelos docentes em formação e auxílio na revisão dos textos produzidos pelas turmas em que realizaram seus estágios.

A seleção de apenas um acadêmico, como amostra de análise, visa a oferecer uma melhor compreensão dos exemplos em sua relação com as etapas. Outro motivo para a escolha foi a participação do docente em formação no Programa Institucional de Bolsa de Iniciação à Docência - PIBID. Isto tem implicação nas análises, pois as noções de revisão e reescrita já eram de conhecimento do participante quando do início da investigação, da mesma forma que alguns conceitos do dialogismo, devido às disciplinas cursadas em anos anteriores do curso, como a que abordavam os componentes de texto e enunciação, no $2^{\circ}$ ano.

Quanto aos registros, optou-se por abordar somente aqueles referentes ao trabalho prático, uma vez que apresentam a dimensão processual da compreensão teórica, metodológica e prática do docente em formação sobre as etapas de revisão e reescrita. Excluíram-se os registros do levantamento final, pelo entendimento de que sua inserção implicaria outras abordagens, com pouca correspondência aos objetivos do trabalho aqui delineado. 


\section{A revisão pelo viés dialógico}

Nesta seção, são analisados três registros do estudo de caso realizado no contexto da formação docente inicial em Letras. Problematizam-se, nesses registros, a possibilidade de realização de uma proposta de revisão pelo viés dialógico e o consequente amparo metodológico utilizado para essa finalidade. A seguir, o primeiro registro.

\section{Figura 1: Revisão efetuada pelo professor em formação numa fábula}

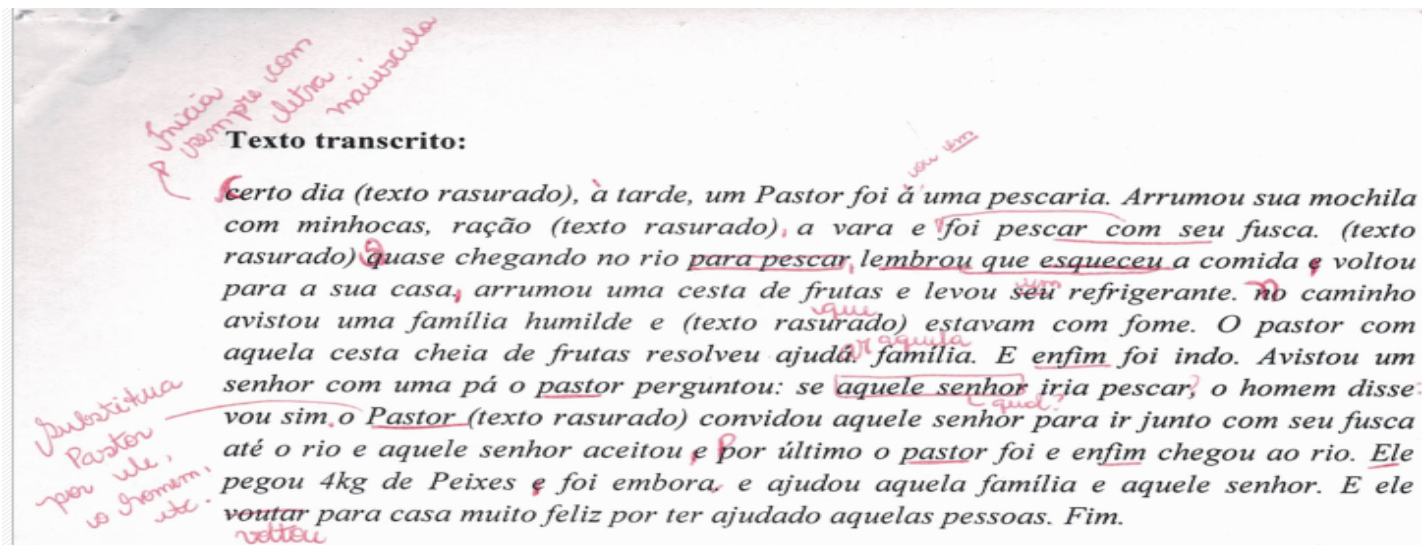

Fonte: Acervo de registros da pesquisa (2020).

Devido à baixa qualidade da imagem, optou-se pela transcrição ${ }^{1}$ do texto, de forma a possibilitar uma melhor compreensão do texto original.

"certo dia, a tarde, um Pastor foi a uma pescaria. Arrumou sua mochila com minhocas, ração a vara e foi pescar com seu fusca. quase chegando no rio para pescar lembrou que esqueceu a comida e voltou para sua casa arrumou uma cesta de frutas e levou seu refrigerante. no caminho avistou uma família humilde e estavam com fome. O pastor com aquela cesta cheia de frutas resolveu ajuda. família. E enfim foi indo. Avistou um senhor com uma pá o pastor perguntou: se aquele senhor iria pescar, o homem disse vou sim o

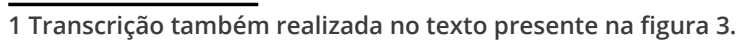


Pastor convidou aquele senhor para ir junto com seu fusca até o rio e aquele senhor aceitou e por último o pastor foi e enfim chegou ao rio. Ele pegou $4 \mathrm{~kg}$ de Peixes e foi embora e ajudou aquela família e aquele senhor. E ele voltar para casa muito feliz por ter ajudado aquelas pessoas. Fim."

O docente recebeu o texto e a tarefa de revisá-lo para, hipoteticamente, solicitar ao aluno uma reescrita. Para tanto, todo o processo que levou à produção da fábula foi explicado, inclusive com a apresentação dos textos trabalhados anteriormente, da proposta e da condição dos indivíduos produtores. Objetivava-se verificar os possíveis conhecimentos teóricos, metodológicos e práticos já constituídos pelo participante em suas experiências pedagógicas e consolidados na revisão da fábula.

Em uma observação de cunho metodológico, constata-se que o sujeito aplicou três metodologias: a correção resolutiva, a correção indicativa (SERAFINI, 1995) e o questionamento da correção textual-interativa (MENEGASSI; GASPAROTTO, 2020; RUIZ, 1998). Há dezenove correções resolutivas espalhadas por todas as linhas do texto, sem exceção, para a abordagem de aspectos como o uso de letra maiúscula em começo de frase, a acentuação, a inserção de palavras e o uso de vírgulas. No que se refere às indicativas, há oito casos nas linhas dois, três, seis, sete, oito e nove, todas elas com traços ou círculos em palavras, de modo a indicar algum aspecto formal. Já o questionamento aparece uma única vez, na linha sete, ao circular a palavra "senhor" para realizar a pergunta "qual?". Isso demonstra a internalização de práticas tradicionais de correção pelo participante em suas experiências pedagógicas, inalteradas mesmo pelo contato com o PIBID e com disciplinas do curso voltadas à enunciação, o que chamou a atenção no momento das análises. Tal constatação é evidenciada pela preocupação com os problemas formais do texto, com o critério de identificar, apontar ou resolver os erros referentes à estrutura superficial.

Há outros dois casos de correção resolutiva: quando na primeira linha o acadêmico insere a letra inicial maiúscula em "certo" 
e orienta "inicia sempre com letra maiúscula"; e na linha oito ao sinalizar a palavra "pastor" e, com isso, estabelece que "substitua Pastor por ele, o homem, etc.". Trata-se de correções resolutivas porque, nos dois casos, o professor dá a solução do problema, não estabelece um diálogo (MENEGASSI; GASPAROTTO, 2019), não instiga o aluno a procurar soluções por conta própria. Na orientação para a letra maiúscula, o problema já está sanado e não há menção à sua repetição ao longo do texto; na troca de palavras, há duas opções dadas que se tornam fechadas. Esses casos demonstram que 0 docente em formação pauta sua intervenção em experiências de correção tradicional.

A análise dos elementos apresentados revela que não ocorre revisão pelo viés dialógico no texto, mas correção no modelo tradicional (MENEGASSI; GASPAROTTO, 2019), o que, possivelmente, se deve ao curto período de contato com perspectivas dialógicas diante de um longo processo de apropriação das correções de cunho tradicional. Ao focar apenas nos elementos superficiais da fábula, o docente inverte a ordem de abordagem e transforma um processo decrescente - da palavra aos elementos gramaticais em processo crescente, ou, em outra análise, estático, já que não avança para as demais camadas do texto, portanto, assume a perspectiva tradicional, sem a possibilidade de uma reflexão teórica e metodológica capaz de, nesse momento, propiciar uma interação dialógica de revisão.

Figura 2: Revisão efetuada no conto de terror

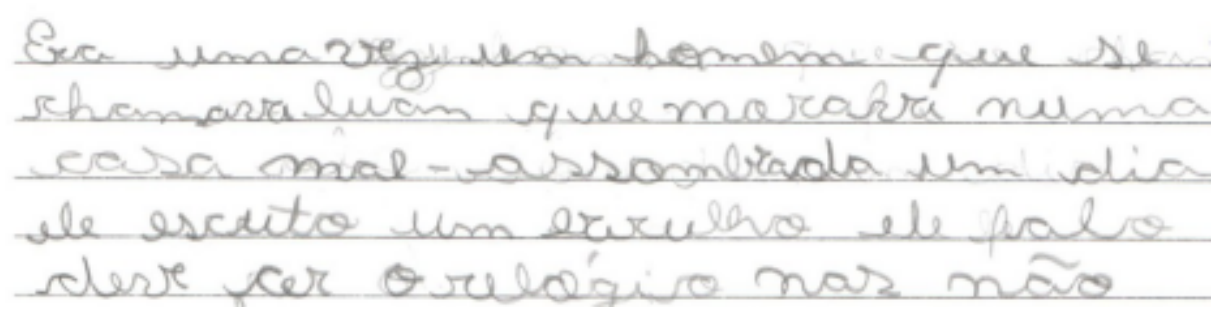


Aluno, você pede imilherar usuis vangumentos vobre vo vascunte. Utente une imicio do paraigrafo vimpre deira um espapo vantes de comefar velia uscrita. Pulvia para ver ve veabminte velu tencto ustá com sentido, suide vom verpetipors upor veremplo uno itrecro "Um dia ule uscutou um barulbo ele e falou...". Preste a tenpá para uque todo vo inicio dos frases vomeam vom la primura letra maibcula, como um "deve ver a velégio", liva u note es poutras frases que ustas lassem tambem. Vexí vesta indo

Essa atividade foi realizada após o estudo teórico das metodologias de revisão junto aos participantes (MENEGASSI; GASPAROTTO, 2020, 2019; RUIZ, 1998; SERAFINI, 1995), expostos no Quadro 2. Nesse exemplo, constata-se que houve um esforço do docente para se aproximar um pouco mais de seu interlocutor e para meIhor orientá-lo, o que se evidencia pela construção de um enunciado orientador e de marcas como vocativo "Aluno", logo no início do comentário - correção textual-interativa (MENEGASSI; GASPAROTTO, 2020) -, uma demonstração de alteração na conduta de comportamento metodológico com a revisão textual, a suscitar o início de reflexão sobre a revisão como um processo dialógico.

Essa reflexão também é assinalada pelas escolhas realizadas pelo sujeito. Se, no exemplo da Figura 1, o foco está exclusivamente em aspectos superficiais do texto e com a preocupação no que se refere à identificação sucessiva de erros; na segunda análise, constata-se que há cuidado em buscar elementos que estão além dessa camada mais imediata de leitura, como demonstrado em: a) "você pode melhorar seus argumentos sobre o assunto"; b) "Releia para ver se realmente seu texto está com sentido". Em ambos os casos, atenta-se já aos aspectos composicionais e de construção de ampliação de uma vontade discursiva. Isso representa uma gra- 
dual mudança de atitude, iniciada pelo contato com outras possibilidades de revisão apresentadas pela intervenção da pesquisa.

Há, também, uma atitude dialógica de não apontar muitas inadequações de uma só vez, já que o corpo do texto não é poluído visualmente com marcações, o que contribui para que o aluno possa fazer uma leitura menos direcionada pela noção de erro que o excesso de marcações gera na visualização. Mesmo as questões pontuais, como recuo de parágrafo, uso de letra maiúscula e repetições, foram orientadas fora do corpo do texto, de forma a melhorar o aspecto visual da revisão e a própria relação com o interlocutor, para melhor compreensão do que se pede.

Aliado ao exposto, infere-se que a revisão, conforme realizada pelo docente em formação, é adequada no sentido de que oferece ao aluno uma direção a respeito do que se espera dele na reescrita, uma alteração significativa em relação ao primeiro exemplo de análise. O fato de visar à reescrita é um indício de que a ação da pesquisa no que concerne às metodologias, com amparo na noção de trabalho em etapas para a produção textual (GERALDI, 1984; GERALDI, 1997 [1991]; FIAD; MAYRINK-SABINSON, 1991; MENEGASSI, 2013; MENEGASSI, 2016), foi apreendido pelo docente em formação, que buscou se colocar em uma posição de coautoria em relação ao seu aluno (GERALDI, 2016).

Por outro lado, a análise do comentário demonstra que o docente em formação ainda apresenta algumas dificuldades no que diz respeito à mobilização de marcas enunciativas na composição do comentário, pela predominância de aspectos superficiais: recuo de parágrafo, repetição de termos e utilização de letra maiúscula em início de frase. Esses aspectos revelam que, aquilo que era trabalhado anteriormente por meio das metodologias de correção resolutiva e correção indicativa, como no exemplo da Figura 1, foi adaptado para o formato de um comentário textual-interativo (MENEGASSI; GASPAROTTO, 2020; RUIZ, 1998), ou seja, o conteúdo da revisão foi apenas relativamente alterado, já que, nesse momento inicial, prevaleceu uma visão de revisão dialógica como aplicação de metodologias específicas. 
No que se refere à revisão na perspectiva dialógica, ainda, observa-se que, devido ao momento de aprofundamento quanto à perspectiva dialógica, não há a atitude de observação da palavra do aluno de modo efetivo, em palavra própria (STELLA, 2005; VOLOCHINOV, 2017 [1929]). O foco dado no comentário se afasta um pouco das possibilidades de potencialização da vontade discursiva do indivíduo que escreveu. Exemplo disso é a passividade diante do aspecto embrionário do conto, representado, principalmente, pela ruptura que se tem ao final: "deve ser o relógio! nas não!!". Considere-se, no entanto, que o docente em formação estava ainda em desenvolvimento de leituras sobre o dialogismo, a ser trabaIhado no processo de revisão, o que explica a tendência de focar em outros elementos, como os formais do texto. É preciso ter ciência de que esse momento é necessário à constituição do sujeito professor, quanto aos conhecimentos a serem angariados e apropriados na revisão textual.

Outra evidência do processo de construção de domínio da concepção dialógica, mesmo que ainda sem critérios específicos de avaliação quanto ao gênero e à finalidade do texto, está presente no trecho "você pode melhorar seus argumentos sobre o assunto". Houve uma tentativa de focar em estruturas que não aquelas superficiais, no entanto, sem uma reflexão mais centrada sobre a especificidade da produção, o que gerou a contradição de solicitar argumentos em um gênero que não é do campo argumentativo. Apesar disso, percebe-se que o trecho do comentário visava ao desenvolvimento do texto na reescrita, o que demonstra certa atitude dialógica e responsiva. A seguir, o terceiro exemplo da pesquisa. 
Revisão textual pelo viés dialógico na formação docente inicial

Paulo Cezar Czerevaty • Cristiane Malinoski Pianaro Angelo • Renilson José Menegassi

Figura 3: Revisão efetuada na crônica
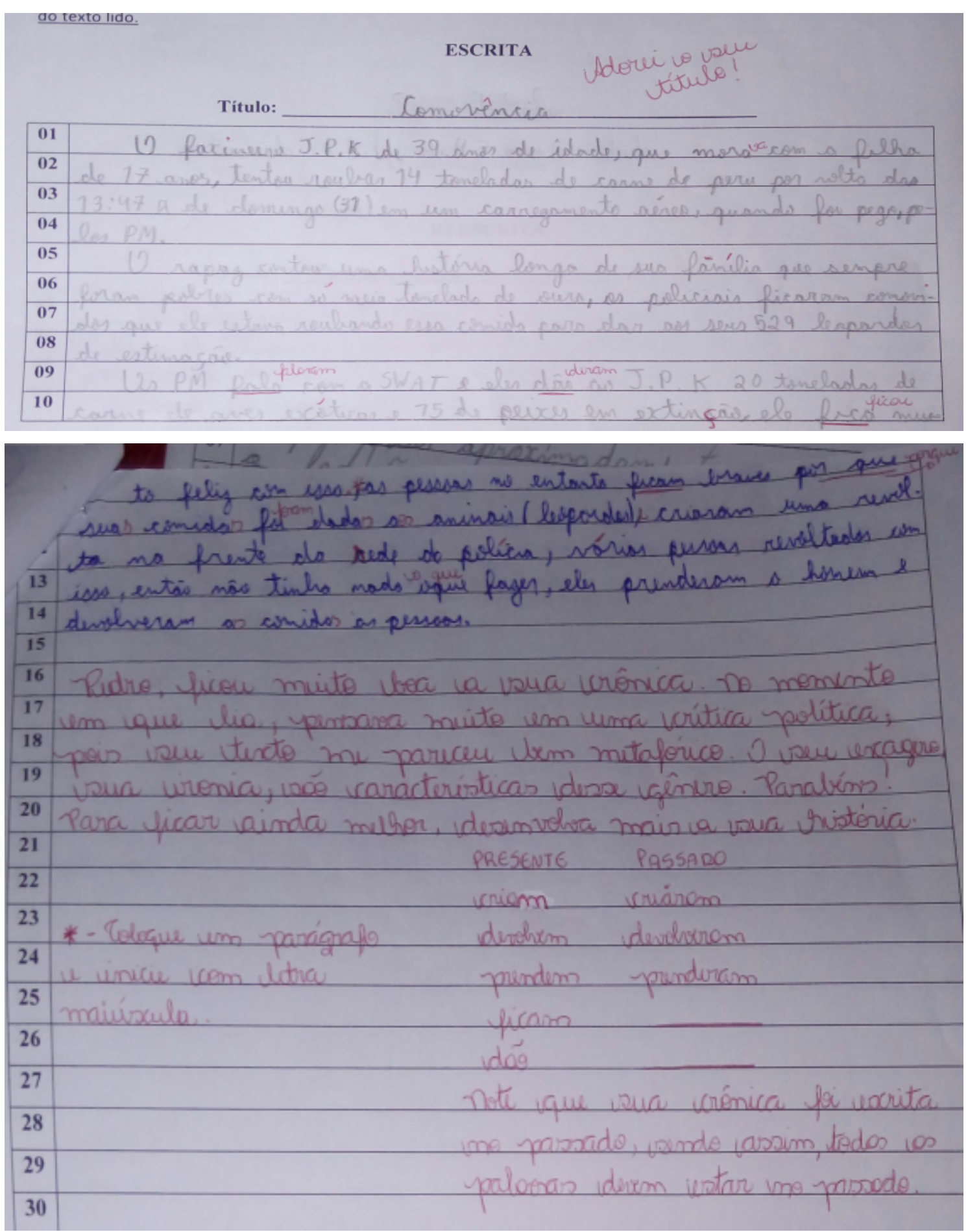

Fonte: Acervo de registros da pesquisa (2020). 


\section{"Comovencia}

O faxineiro J.P.K, de 39 anos de idade, que mora com a filha de 17 anos, tentou roubar 14 toneladas de carne de peru por volta das 13:47 de domingo (31) em um carregamento aéreo, quando foi pego, pelos PM.

O rapaz contou uma história longa de sua familia que sempre foram pobres com só meia tonelada de ouro, os policiais ficaram comovidos que ele estava roubando essa comida para dar aos seus 529 leopardos de estimação.

Os PM fala com a SWAT e eles dão ao J.P.K 20 toneladas de carne de aves exóticas e 15 de peixes em extinção, ele fica muito feliz com isso, as pessoas no entanto ficam bravas por que suas comidas foi dada a animais (leopardos) e criaram uma revolta na frente da rede de polícia, várias pessoas revoltadas com isso, então não tinha nada oque fazer, eles prenderam o homem e devolveram a comida as pessoas".

Para a revisão desse texto, o docente em formação fez o uso de três metodologias: correção resolutiva, correção classificatória e comentário² (MENEGASSI; GASPAROTTO, 2020; RUIZ, 1998; SERAFINI, 1995). Há, portanto, uma compreensão da funcionalidade de cada uso metodológico para determinada intervenção, diferente da mobilização de resolutivas/indicativas apenas, como no exemplo da Figura 1, e textual-interativa, como na Figura 2, para todas as necessidades da revisão. Esses aspectos revelam que o sujeito passou a refletir acerca das próprias escolhas, em virtude das práticas possibilitadas pela pesquisa. Um marco de desenvolvimento a partir dos estudos realizados, conforme demonstra o Quadro 2.

Como primeiro aspecto, observa-se que a palavra do indivíduo que escreveu foi considerada. Tal afirmação é comprovada, de início, com a aceitação da narrativa construída na crônica. Uma leitura desatenta poderia considerar os acontecimentos como absurdos, como uma criação sem nexo, no entanto, o docente compreendeu a lógica por trás daquilo que o aluno criou e pautou sua

2 Destaque-se que o comentário é uma das formas da metodologia de correção textual-interativa, desenvolvida por Menegassi e Gasparotto (2020), a partir de Ruiz (1998). 
análise no aspecto metafórico: "Pedro, ficou muito boa a sua crônica. No momento em que lia, pensava muito em uma crônica política, pois seu texto me pareceu bem metafórico". Nota-se uma diferença dessa atitude em relação às intervenções anteriores. No exemplo da Figura 1, a abordagem se restringiu aos elementos superficiais, sem qualquer comentário sobre os aspectos enunciativos do texto; no exemplo da Figura 2, embora já com tendência a ultrapassar a revisão sobre a superficialidade do texto, não houve orientação quanto às características do enunciado para se posicionar corretamente. No caso da Figura 3, observa-se o domínio da especificidade da produção, aliado à consistência da abordagem.

Nesse trecho do comentário, nota-se que o argumento do docente em formação é plausível. Há nesse texto uma presença do aspecto criativo no desenvolvimento de situações que parecem construir uma metáfora para identificar o Brasil dos últimos anos. O exagero atribuído pelo autor aos acontecimentos da narrativa rememora os fatos quase diários relatados nos jornais, de abusos, de desvios milionários, de farsas de todos os tipos que, pela sua dimensão, também parecem irreais à primeira vista. Assim, mesmo que o aluno não tenha refletido de total consciência acerca disso, as palavras-alheias do diálogo social foram ao encontro de seus anseios e se tornaram palavras-próprias no texto produzido, como respostas ao auditório social (MENEGASSI; GASPAROTTO, 2019; VOLOCHINOV, 2017 [1929]). Isso também aparece condensado na menção à polícia, ao faxineiro, a valores como a solidariedade, tudo considerado na revisão, portanto, com respeito ao princípio da observação da palavra-alheia e da palavra própria. Esse aspecto de revisão não era dominado em outras situações anteriores e passa a ser mobilizado pelo docente a partir da abordagem teórica da perspectiva dialógica estudada, relacionada à metodologia e à prática contextualizadas.

Outro ponto da revisão em que a observação da posição dialógica se sobrepõe à leitura tradicional é na intervenção realizada no título da crônica. A correção tradicional poderia excluir o vocábulo "Comovencia" com o argumento de que não existe e pediria 
para substituí-lo por "comoção", por exemplo, com observância à doutrina do certo e do errado. $O$ docente faz a opção por manter 0 título, elogia a escolha e contribui com o acréscimo do acento circunflexo. Destaque-se que essa ação não infringe nenhuma regra que possa prejudicar a aprendizagem do indivíduo, já que o aluno aplicou a regra de composição de outras palavras para criar um neologismo significativo para o texto. A abordagem, nesse caso, respeita tanto a observação à palavra, uma vez que a utilização de "Comovencia" contribui com a ironia da totalidade da crônica, quanto à entonação valorativa, pelo elogio "Adorei o seu título", logo na parte inicial do bilhete orientador.

O comentário (MENEGASSI; GASPAROTTO, 2020) também aborda a adequação ao gênero e à finalidade ao destacar que "O seu exagero, sua ironia, são características desse gênero", além do próprio início do enunciado, que destaca a construção da narrativa e dos efeitos de sentido, o que implicitamente direciona ao gênero e à finalidade. Ressalte-se que a mobilização de um conceito do dialogismo na revisão não se faz apenas pela intervenção que visa a uma mudança no momento da reescrita; pelo contrário, o que está em jogo é o diálogo sobre o texto e se, pela leitura com viés dialógico, o professor julga que não há necessidade de alteração, o que ele pode fazer é reforçar a adequação já construída, de forma a que se solidifique ainda mais como conhecimento perceptível pelo estudante. Essa atitude, novamente, constrói uma entonação que recupera do extraverbal um relacionamento de cooperação, de coautoria (GERALDI, 2016; VOLOCHINOV, 2013c [1926]), inexistente no exemplo da Figura 1 e embrionário no exemplo da Figura 2.

O docente aborda, em sua revisão, alguns elementos formais que eram necessários para o melhor direcionamento do texto, porém, ao fazê-lo, evita a poluição visual (MENEGASSI, 2013) e, consequentemente, uma entonação-avaliativa de erro (VOLOCHINOV, 2013b [1926]), demonstração de que o valor da linguagem e o papel do interlocutor se faz presente, aspectos do dialogismo que se mostram no processo de apropriação dos conceitos estudados. Ao observar uma inadequação no tempo verbal que prejudicava a 
fruição da leitura, mas que, se solucionada por meio de correções resolutivas ou indicativas, tornaria o texto muito marcado, o acadêmico opta por orientar a alteração também no comentário. Para tanto, monta uma pequena tabela em que, à esquerda, fornece exemplos de verbos no tempo presente e, à direita, do mesmo verbo no tempo passado para, depois, deixar outros dois verbos para que o aluno passe do presente para o passado, tal como necessário no texto. Mobiliza-se, também, o enunciado "Note que sua crônica foi escrita no passado, sendo assim, todas as palavras devem estar no passado", como complemento à revisão.

O cuidado responsivo com o aluno, o trabalho de desenvolvimento de uma intervenção pertinente à produtividade da reescrita e a elaboração de uma orientação importante não só para a melhoria do texto da atividade, mas para a construção do conhecimento do sujeito, demonstram que o docente em formação passou a compreender o processo de revisão em seus aspectos teóricos e metodológicos, além de conseguir desenvolver a prática a partir de uma perspectiva de escrita como trabalho, com nuances do dialogismo.

Essa mudança de compreensão e prática pode ser confirmada, também, pela utilização da metodologia de correção classificatória (SERAFINI, 1995), ao estabelecer o asterisco com um sinalizador dos pontos em que se faz necessária a divisão por parágrafos. A sinalização também é orientada de forma verbal: "Coloque um parágrafo e inicie com letra maiúscula". Novamente, aborda-se determinado problema do texto sem com isso se exagerar nas suas marcações, a gerar poluição visual, a causar desorientação no aluno. O docente em formação compreendeu, pelos estudos e exercícios realizados na pesquisa, que a boa revisão não é aquela que resolve imediatamente e sem critérios todas as inadequações, mas aquela construída com reflexão teórica e metodológica.

Completam a revisão algumas correções de ordem resolutiva no corpo do texto, como a inserção de acentos, vírgulas, além da mudança de alguns tempos verbais não contemplados pelo comentário final. Possivelmente, esses seriam os elementos consi- 
derados de primeira ordem na correção antes da realização da pesquisa, juntamente com as demais marcações resolutivas de elementos abordados dialogicamente no comentário. No entanto, com base nos estudos da concepção dialógica da linguagem, da concepção de escrita como trabalho, das metodologias de revisão e de práticas conjuntas - pesquisador e participante - houve uma mudança de atitude e de prioridade nas abordagens.

Nessa revisão, além de cumprir dialogicamente a observação da palavra, do gênero e da finalidade, dos aspectos responsivos e da construção formal, cumprem-se: a) o cuidado com a entonação; b) a ativa compreensão responsiva para com o interlocutor; c) a adequação e a orientação à reescrita. Quanto ao aspecto a), evita-se a poluição visual e o excesso de marcações no corpo do texto, faz-se uso de vocativos e elogios e, sobretudo, estabelece-se a compreensão correta da realidade da revisão textual. Essa compreensão deriva do fato de se abordar os aspectos centrais que definem o texto como a união de marcas linguísticas e de marcas enunciativas (SOBRAL; GIACOMELLI, 2016), e não apenas as marcas linguísticas pelo formalismo das correções tradicionais. $O$ aspecto $b$ ) realiza-se pela aceitação do texto do aluno, da leitura interpretativa e da atitude de coautoria (GERALDI, 2016). O c) efetiva-se pela abordagem completa propiciada pela adequação metodológica aos conceitos do dialogismo, o que fornece um adequado caminho de reescrita, além de questões como o cuidado na montagem das explicações, a exemplo da tabela com os tempos verbais.

Dessa forma, o terceiro exemplo fornece uma abordagem de revisão mais efetiva, que extrapola a puramente formal ou o uso metodológico por si mesmo, a unir os conceitos do dialogismo e as metodologias de revisão destacadas pela Linguística Aplicada. Na primeira parte da pesquisa, verificava-se que o professor em formação mantinha um alinhamento com as concepções tradicionais, assumia o papel de corretor de textos, pois o breve contato com disciplinas acerca da enunciação e com o PIBID não era suficiente para desenvolver uma perspectiva mais dialógica. Na segunda 
parte, houve um avanço nas práticas desenvolvidas pelo docente em formação, devido ao contato com metodologias diversas aplicadas à prática pedagógica; porém, o desenvolvimento teórico-reflexivo ainda se encontrava em curso. A efetivação de uma abordagem dialógica acontece na terceira parte, muito influenciada, certamente, por todo trabalho prático em conjunto, aliado à teoria apreendida.

\section{Considerações finais}

Com base no dialogismo do Círculo de Bakhtin e em pressupostos da Linguística Aplicada sobre os processos de revisão e reescrita, este artigo objetivou discutir a confluência entre o trabaIho teórico sobre o dialogismo na revisão textual e as metodologias e práticas mobilizadas para a execução do processo.

Constatou-se que as revisões sem orientação teórico-metodológica tendem à abordagem de destacar elementos superficiais do texto. No entanto, o pouco aprofundamento não se evidencia apenas pela predominância da utilização de metodologias de correção indicativa ou correção resolutiva (SERAFINI, 1995), mas pela superficialidade da leitura do texto do aluno, sem amparo em conceitos do dialogismo que definam as prioridades na intervenção.

Tal constatação demonstrou, também, que a escolha metodológica é um dos aspectos que direciona ao dialogismo, mas que necessita de sólido amparo teórico, uma vez que o professor pode apenas transferir a abordagem formal que fazia com correções indicativas ou resolutivas para uma das formas de correção textual-interativa (MENEGASSI; GASPAROTTO, 2020; RUIZ, 1998). Do mesmo modo, uma correção resolutiva é passível de ser usada em intervenções dialógicas, já que a definição dessa necessidade vem da observação conceitual.

Assim, mostrou-se que os conceitos do dialogismo orientam produtivamente a intervenção no texto e, por consequência, a seleção metodológica. O conhecimento desses aspectos faz com que 
a abordagem do texto priorize tanto as marcas linguísticas como as marcas enunciativas (SOBRAL; GIACOMELLI, 2016) e possibilite uma revisão de perspectiva dialógica (MENEGASSI; GASPAROTTO, 2019) e uma reescrita mais construtiva.

A progressão evidenciada pelas etapas de intervenção de pesquisa, mediante um trabalho sólido com conceitos e práticas, evidenciou a necessidade de um trabalho amplo e direcionado às etapas de revisão e de reescrita no contexto da formação docente inicial, de modo a romper com a naturalização das concepções tradicionais e possibilitar, aos futuros professores, um olhar reflexivo acerca das produções de seus alunos.

\section{Referências}

BAKHTIN, Mikhail. O texto na linguística, na filologia e em outras ciências humanas. In: BAKHTIN, Mikhail. Os gêneros do discurso. Organização, tradução, posfácio e notas: Paulo Bezerra. Notas da edição russa: Serguei Botcharov. São Paulo: Editora 34, 2016a [1976].

BAKHTIN, Mikhail. Os gêneros do discurso. In: BAKHTIN, Mikhail. Os gêneros do discurso. Organização, tradução, posfácio e notas: Paulo Bezerra. Notas da edição russa: Serguei Botcharov. São Paulo: Editora 34, 2016b [1978].

BAKHTIN, Mikhail. Por uma metodologia das ciências humanas. In: BAKHTIN, Mikhail. Notas sobre literatura, cultura e ciências humanas. Organização, tradução, posfácio e notas: Paulo Bezerra. Notas da edição russa: Serguei Botcharov. São Paulo: Editora 34, 2017 [1975].

BELOTI, Adriana. A formação teórica, metodológica e prática dos conceitos de revisão e reescrita no PIBID de Língua Portuguesa. 2016. 227f. Tese (Doutorado em Letras) - Universidade Estadual de Maringá, Maringá, 2016. Disponível em: http://www.ple.uem.br/defesas/pdf/abeloti.do.pdf. Acesso em: 21 jan. 2019. 
BRAIT, Beth; MELO, Rosilene de. Enunciado/enunciado concreto/enunciação. In: BRAIT, Beth (Org). Bakhtin: conceitos-chave. 4. ed. São Paulo: Contexto, 2010.

FIAD, Raquel S.; MAYRINK-SABINSON, M. Laura T. A escrita como trabaIho. In: MARTINS, M. Helena (Org.). Questões de linguagem. 3. ed. São Paulo: Contexto,1993. p.54-63.

FUZA, Ângela Francine; OHUSCHI, Márcia Cristina Greco; MENEGASSI, Renilson José. Concepções de linguagem e o ensino da leitura em língua materna. Linguagem e Ensino, Pelotas, RS, v. 14, n. 2, p. 479-501, jul./ dez. 2011. Disponível em: http://www.rle.ucpel.tche.br/index.php/rle/ article/view/36. Acesso em: 07 jan. 2019.

GERALDI, João Wanderley. Portos de passagem. 4. ed. São Paulo: Martins Fontes, 1997 [1991].

GERALDI, João Wanderley. Dialogia: do discurso à estrutura sintática. In: RODRIGUES, Rosângela Hammes; PEREIRA, Rodrigo Acosta (Orgs.). Estudos dialógicos e pesquisas em Linguística Aplicada. São Carlos: Pedro \& João, 2016.

HAYES, John R.; FLOWER, Linda. Identifying the Organization of Writing Process. In: GREGG, Lee; STEINBERG, Erwin (Org.). Cognitive processes in writing. New Jersey: Lawrence Erlbaum, 1980, p. 3-30.

MENEGASSI, Renilson José. A revisão de textos na formação docente inicial. In: GONÇALVES, Adair Vieira; BAZARIM, Milene (Orgs.). Interação, gêneros e letramento: a (re)escrita em foco. Campinas: Pontes, 2013. MENEGASSI, Renilson José; CAVALCANTI, Rosilene da Silva de M. Conceitos axiológicos bakhtinianos em propaganda impressa. Alfa, São Paulo, v. 57 (2), 433-449, 2013. Disponível em: https://periodicos.fclar. unesp.br/alfa/article/download/5133/4669. Acesso em: 16 nov. 2018.

MENEGASSI, Renilson José. A escrita como trabalho na sala de aula. In: JORDÃO, Clarissa Menezes (org.). A Linguística Aplicada no Brasil: rumos e passagens. Campinas: Pontes, 2016.

MENEGASSI, Renilson José; GASPAROTTO, Denise Moreira. Revisão textual-interativa: aspectos teórico-metodológicos. Domínios de linguagem, Uberlândia, MG, v. 10, n. 3, 2016. Disponível em: http://www.seer. 
ufu.br/index.php/dominiosdelinguagem/article/view/33021. Acesso em: 07 jan. 2019.

MENEGASSI, Renilson José; GASPAROTTO, Denise Moreira. Revisão dialógica: princípios teórico-metodológicos. Linguagem em (Dis)curso - LemD, Tubarão, SC, v. 19, n. 1, p. 107-124, jan./abr. 2019.

MENEGASSI, Renilson José; GASPAROTTO, Denise Moreira. As práticas de revisão textual-interativa: apontamento, questionamento e comentário. In: FUZA, A. F. et al. (Orgs.) Interação e escrita no ensino de língua. Campinas, SP: Pontes Editores, 2020.

RUIZ, Eliana Maria Severino Donaio. Como se corrige redação na escola. 1998. 208f. Tese (Doutorado em Linguística) - Universidade Estadual de Campinas, Instituto de Estudos da Linguagem, Campinas, SP, 1998. Disponível em: http://repositorio.unicamp.br/jspui/handle/ REPOSIP/269074. Acesso em 09 jan. 2019.

SERAFINI, Maria Teresa. Como escrever textos. Trad. de Maria Augusta Bastos de Mattos. Adaptação: Ana Luísa Marcondes Garcia. 7. ed. São Paulo: Globo, 1995.

SOBRAL, Adail; GIACOMELLI, Karina. Gêneros, marcas linguísticas e marcas enunciativas: uma análise discursiva. In: SOUZA, Sweder; SOBRAL, Adail (Orgs.). Gêneros, entre o texto e o discurso: questões conceituais e metodológicas. Campinas: Mercado de Letras, 2016.

STELLA, Paulo Rogério. Palavra. In: BRAIT, Beth (Org). Bakhtin: conceitos-chave. São Paulo: Contexto, 2010.

VOLOCHÍNOV, Valentin Nikolaevich. A construção da enunciação. In: VOLOCHÍNOV, Valentin Nikolaevich. A construção da enunciação e outros ensaios. Organização, tradução e notas: João Wanderley Geraldi. Edição e supervisão da tradução: Valdemir Miotello. São Carlos: Pedro e João Editores, 2013a [1930].

VOLOCHÍNOV, Valentin Nikolaevich. Marxismo e filosofia da linguagem. Problemas fundamentais do método sociológico na ciência da linguagem. Tradução, notas e glossário de Sheila Grillo e EkaterinaVólkova Américo. Ensaio introdutório de Sheila Grillo. São Paulo: Editora 34, 2017 [1929], 373p. 
Revisão textual pelo viés dialógico na formação docente inicial

Paulo Cezar Czerevaty • Cristiane Malinoski Pianaro Angelo • Renilson José Menegassi

VOLOCHÍNOV, Valentin Nikolaevich. Palavra na vida e a palavra na poesia. Introdução ao problema da poética sociológica. In: VOLOCHÍNOV, Valentin Nikolaevich. A construção da enunciação e outros ensaios. Organização, tradução e notas: João Wanderley Geraldi. Edição e supervisão da tradução: Valdemir Miotello. São Carlos: Pedro \& João editores, 2013b [1926].

YIN, Robert K. Estudo de caso: planejamento e métodos. 3. ed. Trad. de Daniel Grassi. Porto Alegre: Bookman, 2005. 